\title{
Aeration Control for Nitrogen Removal in a Small-Scale Oxidation Ditch
}

\author{
TERUHISA YOSHIDA', HIDEAKI HAMADA ${ }^{1}$, and MASANORI FUJITA ${ }^{2}$ \\ 'Engineering Research Laboratory, Hitachi Kiden Kogyo Ltd. \\ /3-11-1, Shimosakabe, Amagasaki, Hyogo 661-8501, Japan \\ ${ }^{2}$ Department of Environmental Engineering, Osaka University \\ /2-1,Yamadaoka, Suita, Osaka 565-0871, Japan
}

\begin{abstract}
It is not always easy to keep high efficiency of nitrogen removal in a small-scale oxidation ditch, because its inflow rate generally changes significantly over time, especially for public sewerage facilities without a flow equalization tank. Based on experiments in a real oxidation ditch, a method of combining a DO meter and a timer was found to be useful for controlling intermittent aeration. In this method, a DO set value was used to stop the aerobic condition, and a timer set value was used to keep the anaerobic condition. The DO and timer set values effective for both nitrification and denitrification were about $0.5 \mathrm{mg} / l$ and 1 hour, respectively. A T-N removal efficiency of approximately $90 \%$ was achieved under the most effective condition. It was supposed that the effective DO set value was influenced by the installation position of the DO probe and the total capacity of aerators per volume of the aeration tank. However, this study suggested that the DO set value could be determined by finding the rapid rise of the DO concentration, because it rose rapidly as soon as nitrification was completed.
\end{abstract}

Keywords : oxidation ditch, nitrification, denitrification, DO concentration

\section{INTRODUCTION}

Recently, oxidation ditch plants have been constructed throughout the country, especially in rural areas, because the oxidation ditch process is economical and easy to maintain. In this process nitrification is easily achieved because of the long SRT (solids retention time), and denitrification is simultaneously achieved with reasonable aeration control $^{1)-5}$.

It is generally known that nitrogen is removed by the presence of aerobic and anaerobic zones. Liu et al. ${ }^{1)}$ mentioned that optimum operations were obtained when the anoxic zone accounted for $45-55 \%$ of the total volume of the oxidation ditch. Sato et $a l^{4,5)}$ found that a T-N removal efficiency of over 90 $\%$ was achieved when a DO (dissolved oxygen) probe was installed at the position of the boundary between aerobic and anaerobic zones, and the DO concentration was controlled within the limits of $0.05-0.1 \mathrm{mg} / l$, through adjusting the revolution rate of a surface aerator.

These methods are based on the control of aerobic and anaerobic zones, and they can be adopted in an oxidation ditch consisting of a long circular channel. However, they are considered of no use for a small-scale oxidation ditch consisting of a short channel.

In the complete mixing tank, it is known that intermittent aeration is useful for achieving nitrification and denitrification simultaneously ${ }^{6}$. Similarly in a small-scale oxidation ditch, the method to simply repeat aerated and non-aerated conditions by a timer without using sensors is adopted ${ }^{7)-9)}$. This method might be useful for oxidation ditches regarded as complete mixing. However, for 
elliptical and horseshoe-shaped aeration tanks, it must be difficult to keep a high efficiency of nitrogen removal, because the inflow rate generally changes much over time.

In this study, a method of combining a DO meter and a timer was adopted to control intermittent aeration. Yamamoto et al. ${ }^{10)}$ proved that a stable performance of nitrogen removal was obtained in an elliptical oxidation ditch by using a similar method to that in this study. In their system a flow equalization tank was set up in the former step of the ditch, and a channel of the ditch was considered to be short. (The distance from one aeration point to the following aeration point was estimated at $20 \mathrm{~m}$ or less.) Therefore it was considered that the change in the inflow load was considerably small. The influence of its change on the DO concentration was not made clear enough, and the drop of the DO concentration downstream along the channel was not taken into consideration, because of the short channel.

The object of this study is oxidation ditches which have a neutral characteristic between a complete mixing tank and a circulation tank consisting of a long channel in which both aerobic and anaerobic zones can be formed easily. In these ditches, the distance from one aeration point to the following aeration point is estimated to be about $20-100 \mathrm{~m}$.

In order to establish the nitrogen removal technology applicable to a small-scale oxidation ditch mentioned above, some experiments were made in a real oxidation ditch plant, and a numerical analysis was made based on the obtained data. These results made clear the drop of the DO concentration downstream along the channel, and the behavior of nitrogen in the ditch, and the method to determine the DO and timer set values.

\section{MATERIALS AND METHODS}

\section{Experiments for nitrification and denit- rification rates Some experiments were} made in a laboratory, by using mixed liquor and raw sewage in an oxidation ditch plant mentioned below. For the nitrification rate, $\mathrm{NH}_{4}-\mathrm{N}$ or $\mathrm{NO}_{3}-\mathrm{N}$ concentrations were measured every two hours in a reactor having a volume of $5 l$. In order to find the influence of water temperature and the DO concentration on the nitrification rate $\left(\mathrm{K}_{\mathrm{n}}\right)$, three conditions of $12^{\circ} \mathrm{C}, 17^{\circ} \mathrm{C}$, and $22^{\circ} \mathrm{C}$ were selected for water temperature, and four conditions of $0.2,0.5,1$, and $2 \mathrm{mg} / l$ were selected for the DO concentration. The reactor was settled in an incubator, and an aeration controller was used to keep a stable DO concentration. From the change in the $\mathrm{NH}_{4}-\mathrm{N}$ concentration in the early period, the nitrification rate $K_{n}$ was calculated for each condition.

Similarly for the denitrification rate, the equipment mentioned above was used, and raw sewage and $\mathrm{NaNO}_{3}$ solution were added to the mixed liquor to make the $\mathrm{NO}_{3}-\mathrm{N}$ concentration about $30 \mathrm{mg} / l$. The denitrification rate was calculated by the change in the $\mathrm{NO}_{3}-\mathrm{N}$ concentration. Four conditions of $0,0.2,0.5$, and $1 \mathrm{mg} / l$ were selected for the DO concentration, but water temperature was fixed on the condition of $18^{\circ} \mathrm{C}$ on which the outline of nitrogen removal was estimated.

Facilities for on-site experiments Fig. 1 shows an aeration tank in a small-scale oxidation ditch plant, which was used to demonstrate our control method for nitrification and denitrification. The characteristics of the plant are shown in Table 1. The volume of the aeration tank was 775 $\mathrm{m}^{3}$, and four aerators were installed at the center of the tank, as shown in Fig. 1. Two aerators (A) could not only aerate but also agitate without aeration, by shutting off the valve that was set up at the air inlet, while two aerators (B) could only aerate. A DO

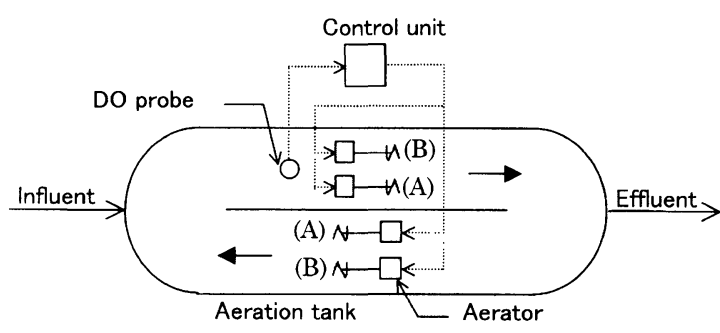

Fig. 1 Schematic of the aeration tank used for demonstration of our method

Aerators (A) : for aeration and agitation without aeration

Aerators $(B)$ : for aeration only 
Table 1 Characteristics of the sewage treatment plant

\begin{tabular}{lc}
\hline Shape of ditch & Elliptical \\
\hline Size of ditch & $4 \mathrm{~m} \times 77.5 \mathrm{~m} \times 2.5 \mathrm{~m} \mathrm{H}\left(775 \mathrm{~m}^{3}\right)$ \\
\hline $\begin{array}{l}\text { Type of aerator } \\
\text { (power } \times \text { number })\end{array}$ & Screw type \\
\hline Max. water treatment capacity & $(\mathrm{A}: 3.7 \mathrm{~kW} \times 2, \mathrm{~B}: 1.5 \mathrm{~kW} \times 2)$ \\
\hline Inflow rate during testing period & $750 \mathrm{~m}^{3} / \mathrm{d}$ \\
\hline Solids retention time & $400-700 \mathrm{~m}^{3} / \mathrm{d}$ \\
\hline MLSS concentration & $15-20$ day \\
\hline DO sensor & $1700-2300 \mathrm{mg} / l$ \\
\hline
\end{tabular}

probe was fastened to a float, to measure the DO concentration near the water surface, and it was installed at the upper stream just near the aerators. Output signals from the DO meter were received by the control unit, which controlled operation of the four aerators based on DO values.

Control method for aeration In this control method, aeration was intermittently carried out. Under the aerobic condition, four aerators simultaneously aerated, while under the anaerobic condition, two aerators (A) agitated and two aerators (B) were stopped. In the control method, the DO concentration was considered to change as shown in Fig. 2 as follows. After the start of aeration, the DO concentration gradually rises and arrives at a DO set value. At this time, the four aerators are altered to the anaerobic condition as mentioned above, and simultaneously the timer is started, to keep the anaerobic condition. After that alteration, the DO

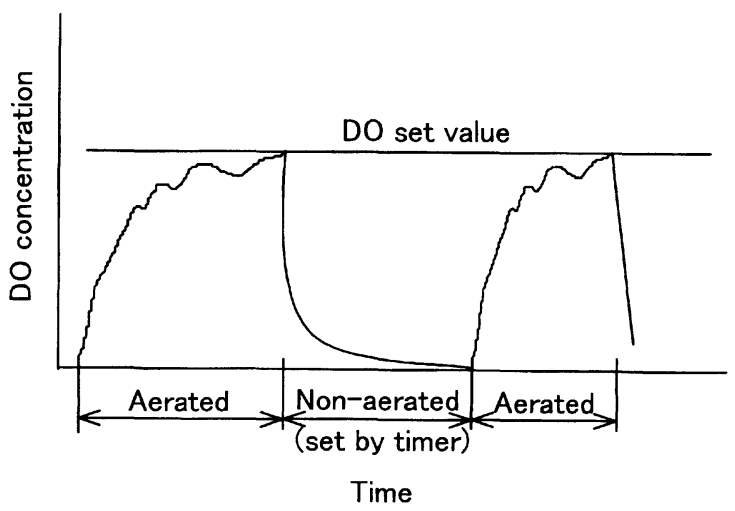

Fig. 2 Profile of the change in the DO concentration concentration rapidly drops. When the timer is up, aeration of the next cycle is started with the control unit.

Operations In series 1 , the DO set value was adjusted, to find a reasonable set value. On the other hand, the set value of the non-aerated timer was fixed at one hour. Operation was conducted for about 3 weeks under one condition of the DO set value, and the performance of nitrogen removal was examined. In series 2 , the DO and timer set values were fixed, and the stability of our control method was assessed by measuring the quality of treated sewage during a long period.

Analytical methods In series 1, raw sewage and treated sewage were sampled, usually every two hours, for two days every week, by automatic samplers. Twelve samples were mixed and analyzed for T-N, K-N (Kjeldahl nitrogen), $\mathrm{NH}_{4}-\mathrm{N}, \mathrm{NO}_{2}-\mathrm{N}, \mathrm{NO}_{3}-\mathrm{N}$, $\mathrm{BOD}$, and SS, as average values of the day. To evaluate the change in a day, a set of twelve samples for the day was analyzed. In series 2 , only treated sewage was analyzed, twice a month. These were analyzed according to the standard methods for sewage wastewater ${ }^{11)}$.

\section{RESULTS}

Lab-scale experiments Fig. 3 shows data plotted as $\left(1 / K_{n}\right)$ vs. $(1 / D O)$. The relation between $\left(1 / K_{n}\right)$ and $(1 / D O)$ was approximated with a straight line. Therefore, it is expressed with the Monod equation as follows.

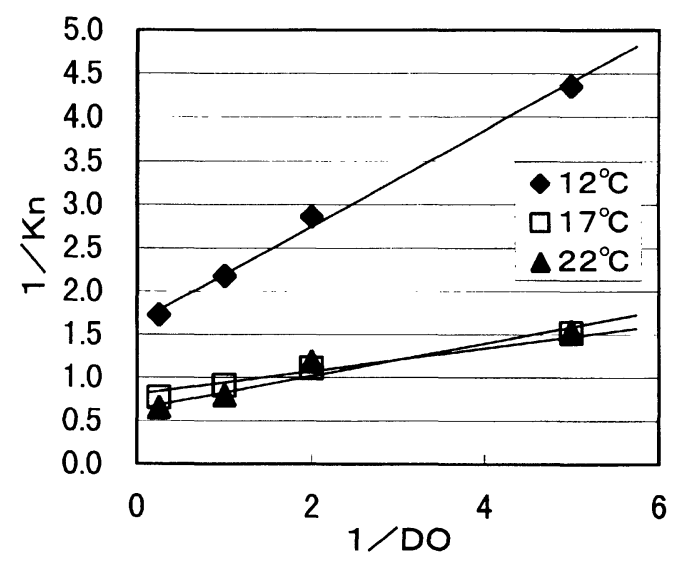

Fig. 3 Relation between (1/DO) and $\left(1 / K_{n}\right)$ 
$\mathrm{K}_{\mathrm{n}}=0.61 \mathrm{DO} /(\mathrm{DO}+0.33) \cdots \cdots \cdot(1)$ at $12^{\circ} \mathrm{C}$

$\mathrm{K}_{\mathrm{n}}=1.32 \mathrm{DO} /(\mathrm{DO}+0.20) \cdots \cdots(2)$ at $17^{\circ} \mathrm{C}$

$\mathrm{K}_{\mathrm{n}}=1.51 \mathrm{DO} /(\mathrm{DO}+0.28) \cdots \cdots(3)$ at $22^{\circ} \mathrm{C}$

The values as the half saturation constant for the DO concentration in the equation were $0.33,0.20$, and $0.28 \mathrm{mg} / l$, and their average value of 0.27 was a little lower than the reported values ${ }^{12)}$ of 0.5 to $2 \mathrm{mg} / l$.

In order to find the relation between water temperature $(\mathrm{T})$ and the maximum nitrification rate $\left(\mathrm{K}_{\max }\right)$, the above results were plotted as $\ln \left(\mathrm{K}_{\max }\right)$ vs. T. As shown in Fig. 4, the relation was almost linear, and accordingly $\mathrm{K}_{\max }$ was expressed by

$$
\mathrm{K}_{\max }=0.228 \exp (0.091 \mathrm{~T})
$$

Fig. 5 shows the relation between the DO concentration and the denitrification rate. The denitrification rate decreased with an increase of the DO, but it did not reach zero. The reason was considered to be because an anaerobic zone existed in the floc of sludge, even if there was some dissolved oxygen out of the floc ${ }^{13)}$. In regard to the method to repeat aerated and non-aerated conditions, it was supposed that denitrification proceeded in parallel with nitrification during the aeration period if the DO concentration was very low.

Series 1 of on-site experiments The DO set value and average quality of treated sewage are shown in Table 2 . At the DO set value of $0.2 \mathrm{mg} / l$, the $\mathrm{K}-\mathrm{N}$ concentration was $6.1 \mathrm{mg} / l$, and nitrification did not proceed sufficiently. However, under three conditions of $0.3,0.4$, and $0.5 \mathrm{mg} / l, \mathrm{~K}-\mathrm{N}$ concentrations were below $2.5 \mathrm{mg} / l$, and the performance for nitrification was almost satisfactory. Electric power consumption means electric energy consumed by four aerators for aeration per day. Since the value of electric power consumption became higher with a rise of the DO set value, it was considered that nitrification proceeded with the increase of supplied oxygen.

The T-N concentration became lower with a rise of the DO set value, and the T-N was $3.5 \mathrm{mg} / l$ at the set value of $0.5 \mathrm{mg} / l$. The

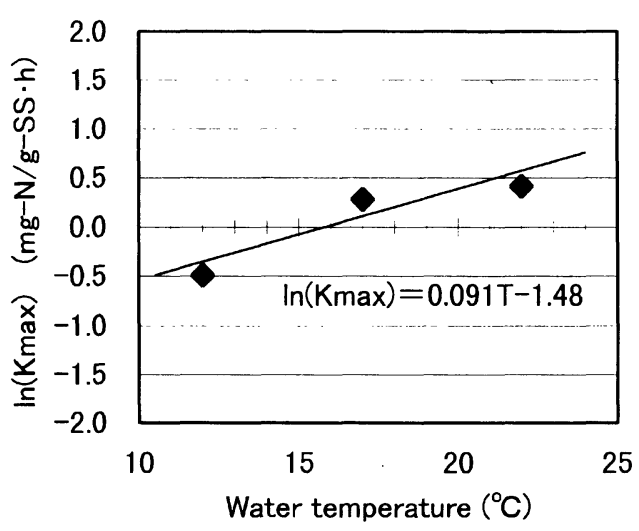

Fig. 4 Relation between water temperature and In $\left(K_{\max }\right)$

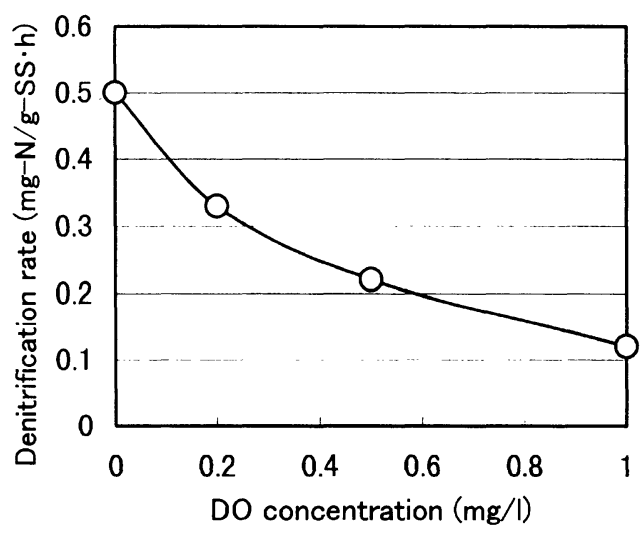

Fig. 5 Relation between the DO concentration and the denitrification rate

Table 2 DO set value and treated sewage quality

\begin{tabular}{ccccccc}
\hline & \multirow{2}{*}{$\begin{array}{c}\text { DO set value } \\
(\mathrm{mg} / l)\end{array}$} & $\begin{array}{c}\text { Electric power } \\
\text { consumption }\end{array}{ }^{1)}(\mathrm{kWh} /$ day $)$ & BOD & SS & $\mathrm{K}-\mathrm{N}$ & $\mathrm{T}-\mathrm{N}$ \\
\hline Run A & 0.2 & 139 & 7.3 & 2.6 & 6.1 & 7.2 \\
\hline Run B & 0.3 & 153 & 7.3 & 3.8 & 2.4 & 5.3 \\
\hline Run C & 0.4 & 157 & 9.3 & 3.2 & 2.3 & 4.5 \\
\hline Run D & 0.5 & 159 & 5.8 & 2.8 & 2.1 & 3.5 \\
\hline
\end{tabular}

1) Total electric power consumption of 4 aerators for aeration 
average $\mathrm{T}-\mathrm{N}$ concentration of raw sewage was approximately $36 \mathrm{mg} / l$, and a T-N removal efficiency of $90 \%$ was achieved. It was considered, from the reason described later, that the efficiency was not improved further even if a DO set value of over $0.5 \mathrm{mg} / l$ was examined.

Fig. 6 shows the change in the BOD load per hour and whether the aerators were or were not in operation, when the DO set value was $0.4 \mathrm{mg} / l$, and the BOD load was calculated from multiplying the BOD concentration by the inflow rate. When the BOD load per hour was high, the DO concentration did not rise because of fast consumption of supplied oxygen, and the four aerators continued to aerate.

As shown in Fig. 6, the aeration time increased with a rise of the BOD load. Namely, this result indicated that the aeration time was automatically changed to correspond to the BOD load. As a whole, aeration tended to continue with a BOD load of over $3 \mathrm{~kg} / \mathrm{hr}$, and to be intermittently conducted with a BOD load of under $3 \mathrm{~kg} / \mathrm{hr}$.

Fig. 7 shows the T-N concentration of treated sewage sampled every two hours and the inflow rate per hour under the condition of RUN C. The inflow rate had a large change in a day, and two peaks, at 8:00 and 18:00. On the contrary, the $\mathrm{T}-\mathrm{N}$ concentration was almost constant and remained under $6 \mathrm{mg} / l$.

Series 2 of on-site experiments Under a constant condition, where the DO and non-aerated timer set values were $0.5 \mathrm{mg} / l$ and 1 hour, respectively, operation was started in September '97 and continued for about one year. Data in Fig. 8 show the T-N and $\mathrm{K}-\mathrm{N}$ concentrations of treated sewage.

All K-N concentrations remained under 4 $\mathrm{mg} / \mathrm{l}$. However, the $\mathrm{T}-\mathrm{N}$ concentration rose in October '97, and exceeded $10 \mathrm{mg} / l$. The reason was found to be that foaming scum covered the surface of the DO probe, and the sensitivity of DO dropped. As such, it was considered that aeration had continued longer than necessary and prevented denitrification, which proceeded under the anaerobic condition. After countermeasures, like cleaning of the DO probe in periodic inspections, were taken, the efficiency was restored, and the T-N concentration dropped. In comparison with T-N and K-N concentrations in the summer, those in the winter were higher, to some extent. This was considered to be because the nitrification and denitrification rates in the winter became lower with the drop of water temperature.

\section{DISCUSSION}

Location of the DO probe and the DO set value for nitrification Fig. 9 shows the change in the DO concentration at the DO set value of $0.5 \mathrm{mg} / l$ in series 2 . Watching DO concentrations at the stop of aeration, we found that almost all DO concentrations reached about $0.6 \mathrm{mg} / l$, although the set value was $0.5 \mathrm{mg} / l$. This was because the timer relays both operated to keep aeration for 15 minutes irrespective of the DO concentration,

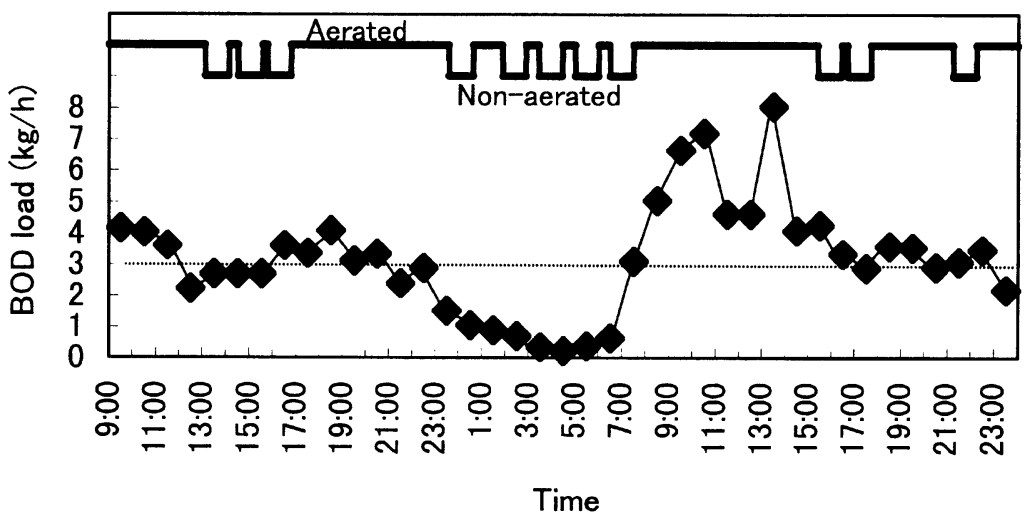

Fig. 6 Change in the BOD load of the influent flow and the state of aerators 


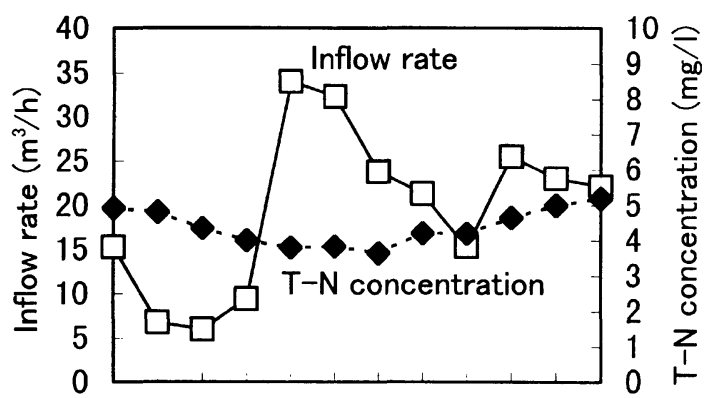

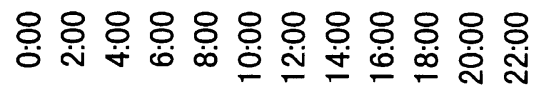

Time

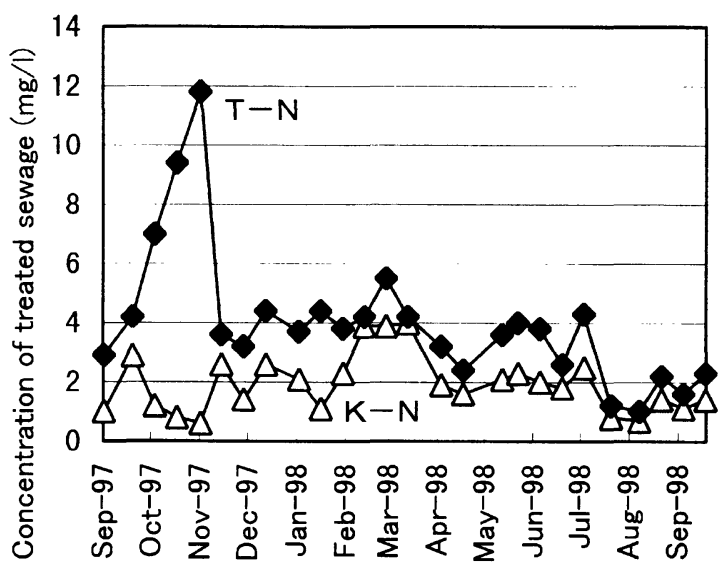

Fig. 8 Changes in $\mathrm{T}-\mathrm{N}$ and $\mathrm{K}-\mathrm{N}$ concentrations of treated sewage

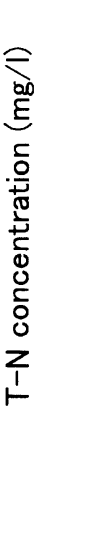

Fig. 7 Changes in the inflow rate and the T-N concentration of treated sewage

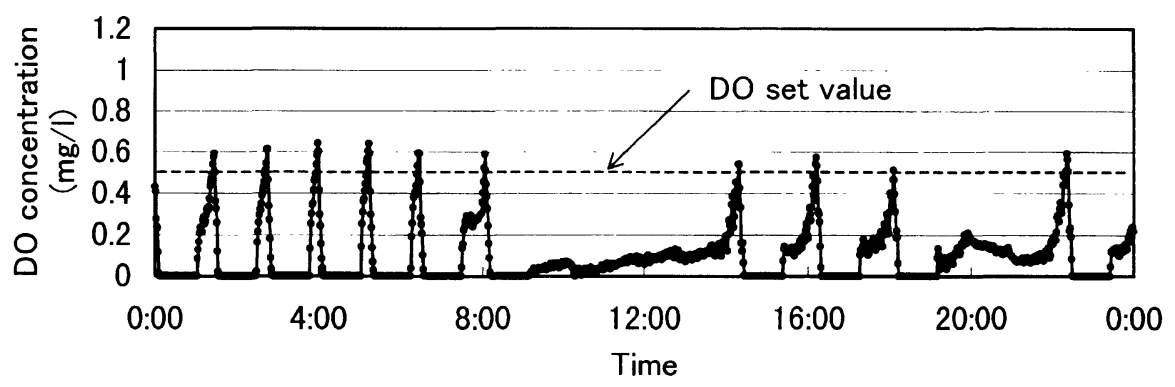

Fig. 9 Change in the DO concentration at the DO set value of $0.5 \mathrm{mg} /$ I

and to exclude the rise of DO signals by noise. Aeration starting at 9 a.m. continued for 5 hours because of the high load of sewage flowing into the aeration tank during this period. The DO concentration was mostly stable at below $0.2 \mathrm{mg} / l$, and afterward it rose rapidly and arrived at the DO set value. The reason for the rapid rise, as mentioned below, was considered to be because nitrification was almost completed, and the consumption rate of oxygen decreased rapidly.

In Fig. 9, aeration was stopped 11 times per day. Data in Fig. 6, taken on another day, show that aeration was stopped 8 times per day. In series 2 , when the operating condition was fixed, the number of aeration-stoppage varied between 5 and 12 times. On the other hand, aeration time in one cycle varied between 0.25 and 8 hours. As mentioned before, K-N and T-N concentrations remained at low values, except for a certain period in series 2 . With this control method, nitrification and denitrification can proceed effectively by changes in the number of aeration times per day and the aeration time per cycle, even if the inflow rate and concentration have a large change.

In order to find the relation between the distance from the aeration point and the DO concentration, a survey of DO concentrations was carried out 5 times at 4 points along the flow of the aeration tank. Data in Fig. 10 show that DO concentrations decreased with greater distance from the aeration point. For all of the 5 times, the slope of the DO curve was similar and was approximately 0.01 $\mathrm{mg} / \mathrm{l} / \mathrm{m}$, on average. This result indicated that the DO curve shown in Fig. 9 moved in 
parallel when the DO probe was moved to another point along the flow. It was considered, therefore, that the rapid rise of the DO concentration appeared like Fig. 9, irrespective of the location of the DO probe.

In this experiment, the DO concentration rose rapidly when the concentration was $0.2^{-}$ $0.4 \mathrm{mg} / l$. This result indicated that the DO set point of $0.5 \mathrm{mg} / l$ was effective for nitrogen removal. In order to determine the DO set point in another oxidation ditch, the DO value at which the DO concentration rises rapidly should be found, because its value varies with the location of the DO probe, MLSS in an aeration tank, and so on. When the DO set value is set at slightly higher than the DO-concentration-rapid-rise value, there is no doubt that both nitrification and denitrification will be sufficiently achieved.

Assumption for numerical analysis A numerical analysis was made based on the condition in Fig. 9, in order to comprehend the change in the concentration of nitrogen in the aeration tank, and the influence of the non-aerated time on the removal of nitrogen, and the difference between the concentration in the aeration tank and that in the settling tank.

Inflow rates and T-N concentrations were assumed as shown in Fig. 11. The values of the inflow rate were data measured during the same day as that in Fig. 9, and T-N concentrations of raw sewage were assumed based on the result investigated at a time close to that in Fig. 9.

Concerning the nitrification rate, a half saturation constant value for the DO concentration in the Monod equation was 0.27 $\mathrm{mg} / l$ on the average from the result of the lab-scale experiments. Because the DO concentration in this aeration tank ranged from zero to over $0.5 \mathrm{mg} / l$, the influence of the DO concentration was not negligible. Nakamura et al. ${ }^{14)}$ showed that the nitrification rate was almost constant at the $\mathrm{NH}_{4}-\mathrm{N}$ concentration of over $0.3 \mathrm{mg} / l$. Because the actual $\mathrm{NH}_{4}-\mathrm{N}$ concentration was considered to be over $0.5 \mathrm{mg} / l$, the influence of the $\mathrm{NH}_{4}-\mathrm{N}$ concentration could be neglected. Consequently the nitrification rate was expressed as a function only of the DO concentration.

The average water temperature $(\mathrm{T})$ in Fig. 9 was $18^{\circ} \mathrm{C}$. When $\mathrm{T}$ was $18^{\circ} \mathrm{C}, \mathrm{K}_{\max }$ was 1.173 by equation (4). By means of adopting the average value of 0.27 as the half saturation constant for the DO concentration, the nitrification rate at $18^{\circ} \mathrm{C}$ was estimated by the equation

$$
\mathrm{K}_{\mathrm{n}}=1.17 \mathrm{DO} /(\mathrm{DO}+0.27)
$$

Concerning the denitrification rate, a half saturation constant value for the $\mathrm{NO}_{3}-\mathrm{N}$

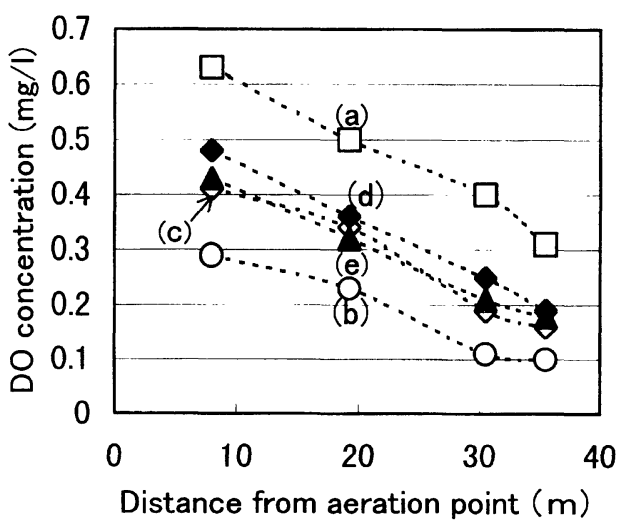

Fig. 10 Relation between the distance from the aeration point and the DO concentration (a): the first survey in series 2 (b): the second survey in series 2 (c): the third survey in series 2 (d): the first survey in Run $D$ of series 1 (e): the second survey in Run $D$ of series 1

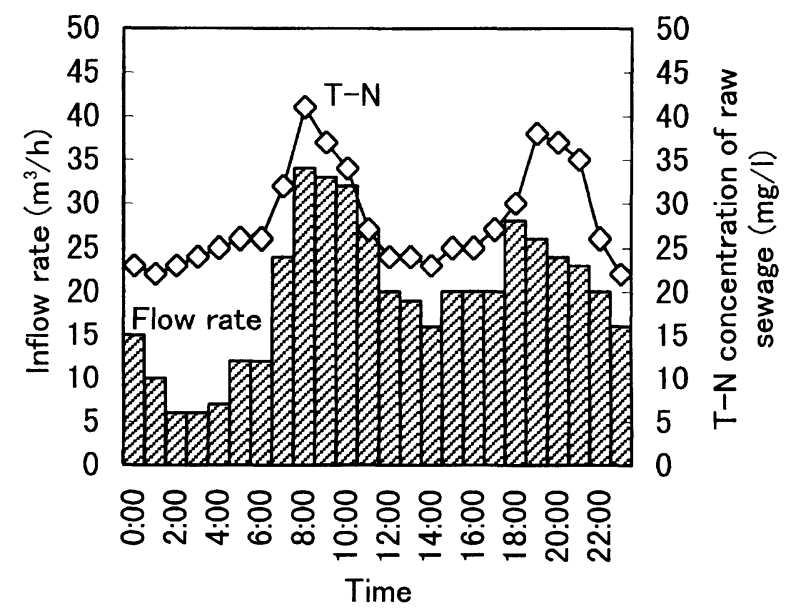

Fig. 11 Assumed condition as to the change in the inflow rate and $\mathrm{T}-\mathrm{N}$ concentration 
concentration in the Monod equation was reported to be $0.06-0.2 \mathrm{mg} / l^{15)}$. In this aeration tank, the $\mathrm{NO}_{3}-\mathrm{N}$ concentration was normally over $0.5 \mathrm{mg} / l$, and the influence of the $\mathrm{NO}_{3}-\mathrm{N}$ concentration on the denitrification rate was considered to be small. Therefore the denitrification rate was estimated by Fig. 5 which expressed a relation between the DO concentration and the denitrification rate.

On the other hand, it is known that the nitrogen concentrations are almost the same anywhere along the channel in the oxidation ditch, although the DO concentration drops downstream along the channel ${ }^{16)}$. This is because the nitrification and denitrification rates are considerably small compared with the rate of the DO drop.

Therefore concerning the DO concentration, its change along the channel was considered, and the nitrogen concentrations were assumed to be the same everywhere in the aeration tank (oxidation ditch). It was assumed that the DO concentration at the position of the DO probe was the measured value in Fig. 9, and all of $\mathrm{T}-\mathrm{N}$ in raw sewage existed in the form of $\mathrm{NH}_{4}-\mathrm{N}$. Moreover, it was assumed that neither nitrification nor denitrification were caused in the settling tank.

Procedure of numerical analysis The calculation of the nitrogen concentration was made every 15 minutes. Based on the nitrogen concentration at the time $\tau$ (i), the concentration at the time $\tau(\mathrm{i}+1)$ was calculated as follows.

1) The amount of T-N $\left(=\mathrm{NH}_{4}-\mathrm{N}\right)$ which increased in 15 minutes was obtained by multiplying the inflow rate by the T-N concentration, which were shown in Fig. 11, respectively. The amount was expressed by $\Delta \mathrm{IN}(\mathrm{i})$.

2 ) Based on the DO concentration at the time $\tau$ (i) shown in Fig. 9 and the slope of the DO curve $(=0.01 \mathrm{mg} / \mathrm{l} / \mathrm{m})$, the average DO value in the tank was calculated.

3 ) The nitrification rate in the average DO value was calculated from equation (5).

4 ) The amount of $\mathrm{NH}_{4}-\mathrm{N}$ which decreased with nitrification was calculated based on the nitrification rate and the amount of SS (suspended solids) in the aeration tank. The amount of nitrified $\mathrm{NH}_{4}-\mathrm{N}(=\mathrm{K}-\mathrm{N})$ was expressed by $\Delta N$ (i).

$5)$ The amount of $\mathrm{NO}_{3}-\mathrm{N}$ which decreased with denitrification was calculated based on the denitrification rate shown in Fig. 5 and the amount of SS in the aeration tank. The amount of denitrified $\mathrm{NO}_{3}-\mathrm{N}(=\mathrm{T}-\mathrm{N})$ was expressed by $\Delta \mathrm{DN}$ (i).

6 ) When the amount of K-N remaining in the aeration tank at the time $\tau$ (i) was expressed by $\mathrm{KN}(\mathrm{i}), \mathrm{KN}(\mathrm{i}+1)$ at the time $\tau$ (i+1) was obtained by

$$
\mathrm{KN}(\mathrm{i}+1)=\mathrm{KN}(\mathrm{i})+\Delta \mathrm{IN}(\mathrm{i})-\Delta \mathrm{N}(\mathrm{i})
$$

7 ) When the K-N concentration at the time $\tau$ (i) was expressed by CKN (i), CKN (i+1) was calculated by dividing $\mathrm{KN}(\mathrm{i}+1)$ by the volume $(\mathrm{V})$ of the aeration tank.

8 ) Similarly when the amount and concentration of $\mathrm{NO}_{3}-\mathrm{N}$ at the time $\tau$ (i) were expressed by $\mathrm{NO}(\mathrm{i})$ and $\mathrm{CNO}(\mathrm{i})$, respectively, $\mathrm{NO}(\mathrm{i}+1)$ was obtained by $\mathrm{NO}(\mathrm{i}+1)=\mathrm{NO}(\mathrm{i})+\Delta \mathrm{N}(\mathrm{i})-\Delta \mathrm{DN}(\mathrm{i})$ CNO (i+1) was calculated by dividing NO (i+1) by $\mathrm{V}$.

9 ) When the T-N concentration at the time $\tau$ (i) was expressed CTN(i), CTN (i+1) was calculated by

$$
\text { CTN }(i+1)=\mathrm{CKN}(\mathrm{i}+1)+\mathrm{CNO}(\mathrm{i}+1)
$$

10) The nitrogen concentrations in mixed liquor flowing into the settling tank was given by CKN (i+1), CNO (i+1) and CTN (i+ 1). Each concentration of nitrogen in the settling tank was calculated based on the amount and concentration of influent sewage, and the assumption that the settling tank was a complete mixing tank.

Verification of analytical result Fig. 12 shows the T-N concentrations of treated sewage that overflows the settling tank. Under the condition that the calculated and measured $\mathrm{T}-\mathrm{N}$ values were the same at 0:00, $\mathrm{T}-\mathrm{N}$ concentrations were calculated and plotted every hour in Fig. 12. Compared with the measured value every two hours, the calculated value changed somewhat gradually, but indicated almost the same value.

Therefore this method was considered to be useful for comprehending the change in the concentration of nitrogen in the aeration tank, and the influence of the non-aerated time.

Outline of nitrification and denitrification in the aeration tank The result of the calculation is plotted in Fig. 13 as follows. 
Fig. 13 shows the change in the K-N and $\mathrm{T}-\mathrm{N}$ concentrations in the aeration tank. These values changed largely with the change of the inflow load in Fig. 11, although the T-N concentration of treated sewage was relatively stable. The dotted lines express the time when aeration was stopped. K-N concentrations at the time were $0.4-0.6 \mathrm{mg} / l$, except for the case before 7:00 a.m., when aeration was maintained for 15 minutes, as mentioned before, by the sequence timer, irrespective of the DO concentration, because the load of the influent flow was very low. This result indicated that the nitrification rate rapidly dropped when the $\mathrm{K}-\mathrm{N}\left(=\mathrm{NH}_{4}-\mathrm{N}\right)$

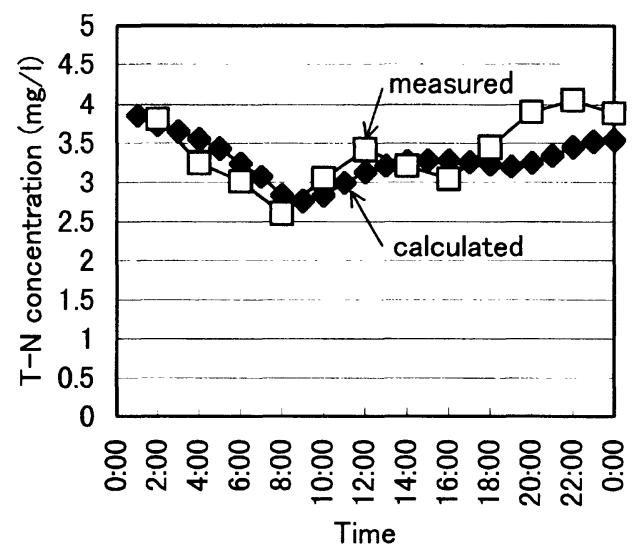

Fig. 12 Change in the T-N concentration of treated sewage from the settling tank concentration decreased to $0.4-0.6 \mathrm{mg} / l$. It was considered, therefore, that the DO concentration increased to the DO set point with a decrease of the consumption rate of oxygen, and aeration was stopped.

Non-aerated time for denitrification Previous experiments proved that the performance of denitrification dropped by degrees with longer non-aerated time (set within 1-3 $\mathrm{hrs}$ ), in the intermittent aeration process using the timer. So the influence of the non-aerated time on nitrogen removal was assessed. T-N concentrations in the aeration tank were calculated based on the method described above, when the non-aerated time was changed from 1 hour to $0.5,2$, or 3 hours. Before calculating, it was assumed that aeration was stopped at an $\mathrm{NH}_{4}-\mathrm{N}$ concentration below $0.6 \mathrm{mg} / \mathrm{l}$, at which time the nitrification rate rapidly dropped and the DO concentration increased to the DO set point.

Data in Fig. 14 prove that the T-N concentration in the aeration tank rises with an increase of the non-aerated time. Although the time for the anaerobic condition was short when the non-aerated time was 0.5 hours, denitrification proceeded successfully. This was because denitrification proceeded in parallel with nitrification during the aeration period. It was considered that 0.5 or 1 hour was adaptable as the timer set value for the

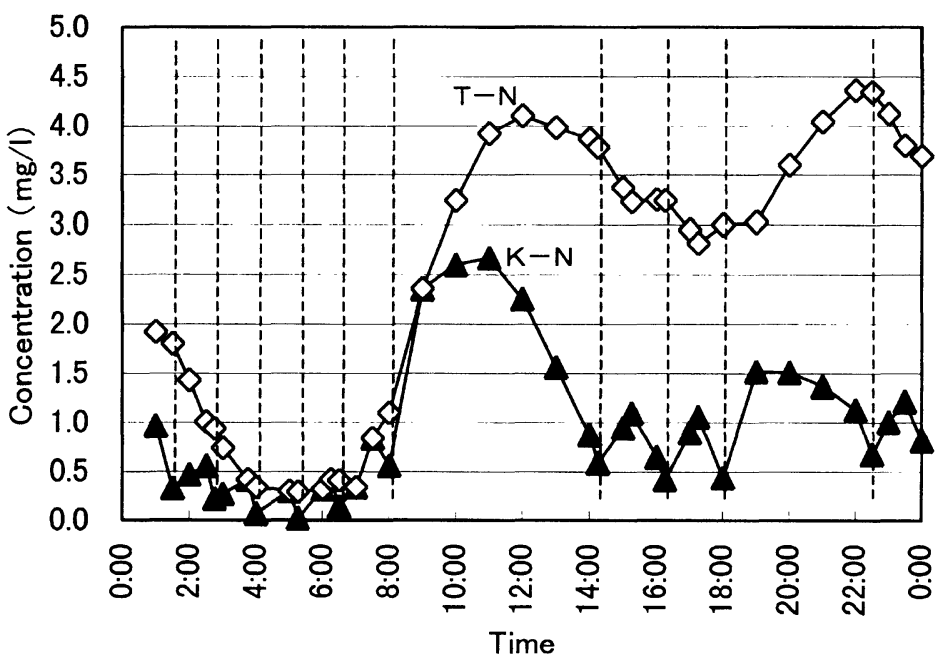

Fig. 13 Change in calculated $\mathrm{K}-\mathrm{N}$ and $\mathrm{T}-\mathrm{N}$ concentrations in the aeration tank 


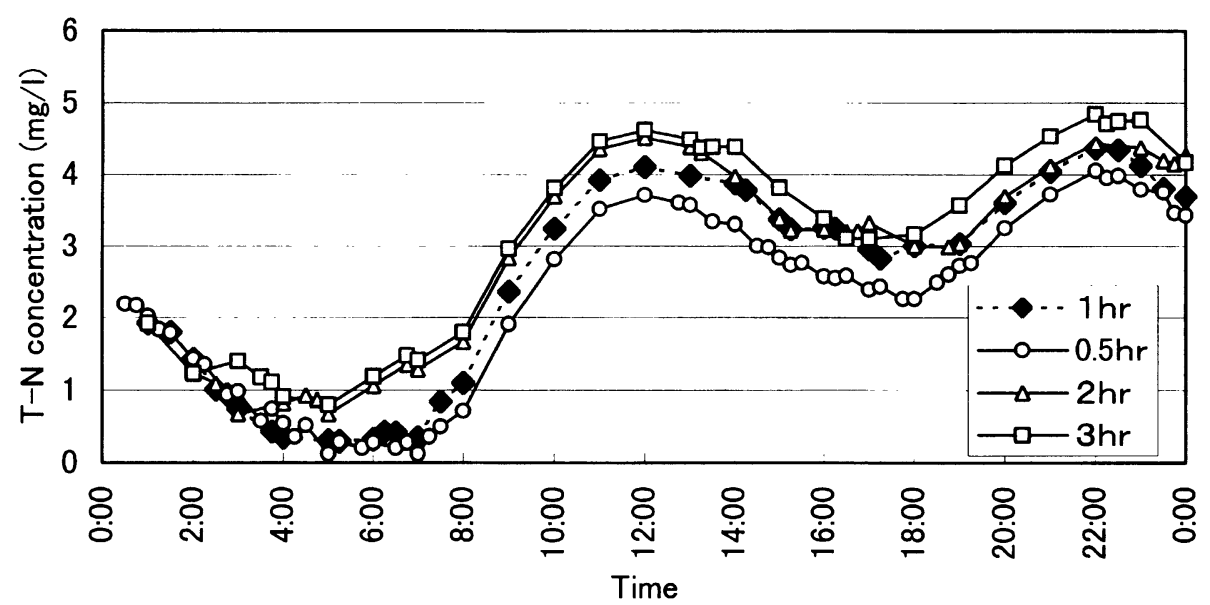

Fig. 14 Change in the calculated T-N concentration in the aeration tank as to four conditions of non-aerated time

non-aerated time, from the viewpoint of practical use.

\section{SUMMARY}

In order to keep a high efficiency of nitrogen removal in a small-scale oxidation ditch, a method to control aeration was demonstrated. A DO probe was installed in an aeration tank of $775 \mathrm{~m}^{3}$, and based on output signals from a DO meter, intermittent aeration was conducted, in which all aerators were simultaneously operated and stopped. The results are summarized as follows:

(1) The method to combine a DO meter and a timer for the non-aerated condition was very useful. The DO set value was used to stop the aerobic condition, and the timer set value was used to keep the anaerobic condition. When the DO and timer set values were $0.5 \mathrm{mg} / l$ and 1 hour, respectively, T-N removal efficiency of approximately $90 \%$ was achieved.

(2) It was considered that the DO set value effective to control aeration was influenced by the installation position of the DO probe and the total power of aerators per volume of the aeration tank. However, it can be determined by finding the rapid rise of $\mathrm{DO}$, because the $\mathrm{DO}$ concentration rises rapidly as soon as nitrification is completed.

(3) From detailed analysis based on measurement of the nitrification and denitrification rates, it was proved that the $\mathrm{T}-\mathrm{N}$ concentration in the aeration tank changed largely with the change in the load of influent flow, while that of treated sewage from the settling tank was almost stable.

(4) The detailed analysis also proved that the $\mathrm{T}-\mathrm{N}$ concentration in the aeration tank rose with an increase of the non-aerated time. From the viewpoint of practical use, 0.5 or 1 hour is adaptable as the timer set value for the non-aerated time.

\section{REFERENCES}

1) Liu J. K., van Groenestijn J. W., Doddema H. J., and Wang B. Z. : Influence of the aeration brush on nitrogen removal in the oxidation ditch, European Water Pollution Control, Vol. 6, No. 4, 25-30 (1996)

2 ) Nakamura Y., Ishikawa M., and Nakanishi H. : The study on the efficiency improvement of oxidation ditch process, Environmental Conservation Engineering, Vol. 25, No. 4, 58-65 (1996) (in Japanese)

3 ) Shimizu T., Kudo K., Doro T., and Nasu Y. : Removal of organic, nitrogen and phosphorus substances in a full-scale oxidation ditch, Journal of Japan Sewage Works Association Research (Research Journal No. 6), Vol. 29, No. 345, 41-51 
(1992) (in Japanese)

4) Sato S., Uekake Y., and Fukagawa K. : Gesuidou Kenkyuu Happyoukai Kouensyuu, No. 32, 496-498 (1995) (in Japanese)

5 ) Sato S., Fukagawa K., and Motomura K. : Environmental Conservation Engineering, Vol. 23, No. 11, 10-15 (1994) (in Japanese)

6 ) Oba S. and Sakai Y. : Sewage treatment characteristics by single-stage intermittent aeration system, Journal of Japan Sewage Works Association Research (Research Journal No. 12), Vol. 31, No. 379, 16-33 (1994) (in Japanese)

7 ) Roustan M., Chatellier P., Lefevre F., Audic J. M., and Burvingt F. : Separation of the two functions aeration and mixing in oxidation ditches: Application to the denitrification by activated sludge, Environmental Technology, Vol. 14, 841849 (1993)

8 ) Ozawa H., Suzuki T., Itoh S., Matsui M., and Furihata A. : Naganoken Eikoken Hokoku, No.12, 35-40 (1989) (in Japanese)

9 ) Araki H., Koga K., Inomae K., Awaya Y., and Kusuda T. : Nitrogen removal in oxidation ditch with intermittent aeration, Proc. of Environ. \& Sani. Eng. Reseach, Vol. 22, 241-249 (1986) (in Japanese)

10) Yamamoto $M$. and Terunuma $H$. : Advanced treatment system for domestic waste water using intermittent aeration process controlled by dissolved oxygen, Journal of Resources and Environment, Vol.29, No.8, 31-39 (1993)

11) Japan Sewage Works Assoc. : Standard Methods for the Examination of Wastewater (1984) (in Japanese)

12) Stenstrom M. K. and Poduska R. A. : The effect of dissolved oxygen concentration on nitrification, Water Research, Vol.14, 643-649 (1980)

13) Rittmann B. E., and Langeland W. E. : Simultaneous denitrification with nitrification in single-channel oxidation ditches, J.WPCF, Vol.57, No.54, 300-308 (1985)

14) Nakamura H., Sumino T., and Emori H. : Nitrification characteristics of immobilized microorganisms and suspended sludge in nitrogen removal process, Japanese Journal of Water Treatment Biology, Vol. 34, No.2, 69-82 (1998)

15) Tchobanoglous G. and Burton F. L. : Wastewater engineering, treatment, disposal, and reuse, Metcalf \& Eddy, Inc., 711-726 (1991)

16) Shikano N., Takahashi N., Odashima T., Fukuhara T., Ooba M., and Enari K. : Gesuidou Kenkyuu Happyoukai Kouensyuu, No.32, 313-315 (1995) (in Japanese)

(Submitted 1999. 10. 7) (Accepted 2000. 6. 19) 